\title{
CUSTOMER EXPERIENCE IN OMNI-CHANNEL BANKING SERVICES
}

\begin{abstract}
Theanking industry is experiencing rapid and widespread changes due to advances in technology that go hand-in-hand with the customer demands for real-time, personalized and seamless banking experience. Along with this development, omni-channel orientation is becoming an inherent feature of banking services. However, its role has not yet been thoroughly understood, specifically in this context. The purpose of this study is to create in-depth understanding of how do customers experience omni-banking services and what are the key factors related to their experiences. We identify both actual critical events and imaginings, positive and negative, that are related to the forming of customer experiences and suggest both theoretical and managerial implications based on the results.
\end{abstract}

KEYWORDS Customer experience, omni-channel, critical incident technique, banking service

\section{INTRODUCTION}

The banking industry is currently experiencing rapid and extensive changes due to advances in technology, e.g. immediate payment infrastructures, mobile authentication, block chain and the 'Internet of Things' (IoT) (Light et al., 2016). Consequently, customers are demanding more realtime, personalized and seamless banking experience. Along with technological development and increasing use of smart phones and tablets, omni-channel orientation has become important for a diverse set of banking services. Omni-channel banking offers access to financial services across a variety of channels (e.g. branch, ATMs, call center, internet/online banking and mobile) in an 
integrated way following the idea that "everything should be doable in every channel" (see Rosman, 2015). In relation to this, the three key principles of omni-channel can be defined as seamlessness, optimization and consistency (McKinney, 2014; Rosman, 2015). Saghiri et al. (2017) further describe omni-channels as complex adaptive systems that consist of agents (or entities), connectivity, emergency and autonomy/control. In this study, omni-channel is understood broadly and in general terms, it refers here to an approach that provides a single, seamless, unified experience for the customer across all channels (see also Carroll and Guzman, 2015).

However, banking services are often developed and delivered without adequate understanding of related customer experiences, activities, everyday practices and life, i.e. of customers' value creation (Lähteenmäki and Nätti, 2013). It has been noted that most studies in the banking context have researched banking channels separately (Hoele et al, 2012) although it seems that multi-channel use has been a day-to-day reality for many consumers for a long time (Van Dijk et al, 2006). In addition, existing research in the banking field has mostly focused on adoption of different banking services (Shaikh and Karjaluoto, 2015) and there is only little empirical evidence regarding other relevant aspects of the phenomenon. Most of the recent empirical studies conducted are quantitative in nature and do not provide in-depth understanding of the customer experiences of omni-channel banking services (Tam and Oliveira, 2017). Understanding customer experiences is, however, particularly important for the banking industry for extending customer reach, improving customer retention, enhancing operational efficiency and increasing market share (Skan et al, 2015). Moreover, understanding factors related to customer experience in this particular context is not only of interest to the banking industry but is also relevant for the related industries that together form an ecosystem which builds the omni-banking service experience (see Komulainen et al, 2018). 
Understanding customers' experiences has been acknowledged as one of the most important current research priorities (MSI, 2016). Understanding of the formation of customer experience facilitates the company in differentiating its products and services for creating superior customer value (Jaakkola et al, 2015) and loyalty (Frow and Payne, 2007; Gentile et al, 2007). It is important to consider the customer's perspective since a company is able to develop and improve their experience only by understanding the customer's mental mindset, and thinking processes. Although there has been a growing interest in customer-centric logic and customer's service experience (Heinonen et al, 2013), there are still gaps in our knowledge regarding customer experience in specific contexts (Jaakkola et al, 2015). This study aims to fill in one of these gaps by analysing customer experiences in the banking industry that is one of the fast growing industries driven by digitalization and globalization.

The purpose of this study is to create in-depth understanding of how do customers experience omnichannel banking services and what are the key factors related to their experiences? The study is implemented using Critical Incident Technique (CTI) combined with Event-Based Narrative Inquiry Technique (EBNIT) to get a thorough insight into customers' life contexts and their use of omnichannel banking services. Empirical data has been collected using theme interviews and a diary method, which together provide in-depth insights needed to truly understand customers' experiences. Our study thus contributes to bank marketing theory by suggesting the key factors influencing customer experience in the omni-channel banking context. In addition, it provides managerial implications on how to develop such services to better meet customers' changing needs.

The study this is followed by a discussion of the research methods and empirical analysis on the experiences of the users of omni-channel banking services. Finally, the findings are discussed and the study concludes with the theoretical and managerial implications as well as future research areas 


\section{LITERATURE REVIEW}

The omni-channel approach can be seen as the evolution of the multi-channel and having its origins in the retail industry (Rosman, 2015). According to the multi-channel view, the customer gets a diverse experience across channels and acts as an integrator of information, whereas the omni-channel view focuses on bridging the gaps between different channels with the aim to provide a consistent and seamless customer experience (Rosman, 2015; Saghiri et al., 2017). Based on this, three key principles or factors of omni-channel can be defined as: 1) Seamless interaction between the channels (i.e. seamless transition to a second channel, enabling continuation of what was already started in the first channel), 2) Optimization across channels (i.e. designing tasks and functionalities for different devices adapted to their unique context and strengths), and 3) Consistent experience across channels (e.g. presentation and language or that task models are found consistent over different devices) (see McKinney, 2014; Rosman, 2015).

In their recent study, Saghiri et al. (2017) found out that in order to be successful omni-channel systems need various different enablers, such as Internet accessibility, well-located and well-designed distribution centers, efficient logistics network, cross-channel integration, customer analytics, omnichannel visibility to customers and product digitization. This way the omni-channel system can assure optimal information availability, visibility and consistency across multiple channels, which in turn produces several benefits such as total sales growth, cost savings, synergy and differentiation through value-added service. However, despite the importance and topicality, academic literature on omnichannels in different contexts remains scarce (e.g. Rosman, 2015; Saghiri et al., 2017) which makes it important to study it in the fast developing context of banking services and in relation to customer experience. 
In recent years, interest in service experience and its management has increased considerably in marketing (Heinonen et al, 2010; Dube and Helkkula, 2015). The literature features various definitions of customer service experience (Gentile et al, 2007) emphasising the elements of service process, process effects and outcomes, and customer participation (Tynan and McKechnie, 2009). A common denominator of the definitions and research on customer experience is the emphasis on the individual's mental processes and personal interpretations (Helkkula et al, 2012). According to Helkkula and Kelleher (2010), service experience contains the consumer's previous, current, future and imaginary experiences that develop and change continuously. In other words, all those moments when the service is used, or its use is being planned or remembered, are related to the service experience. Imaginary experiences refer to, for example, what kind of service is considered good or what kind of a context is related to the service, at best. The focal study defines customer experience as an individual's internal and subjective awareness or perception of a service: experience arises in the mind of an individual who is connected to a service on an emotional, physical, intellectual and/or spiritual level, and participates in the service (Holbrook and Hirchman, 1982; Lemke et al, 2011).

The customer experience is temporal by its nature and prone to change (Helkkula et al 2012). Service may seem unpleasant at the time it takes place, however, when considering it afterwards, it may turn out to have been a positive experience. A customer makes choices that $\mathrm{s} / \mathrm{he}$ considers relevant and acts according to previous experiences, external effects and future expectations. Also contextual factors, such as demographic factors, an individual's social and financial situation, cultural, psychological and other personality features affect the behavior and experiences of an individual (Constantinidesin, 2004). The individual's experience is also always affected by the social context and situation in which the individual operates. Hence, although experience is subjective to the individual, it is also social, as individuals live and experience in a social world (Helkkula et al, 2012; 
McColl-Kennedy et al, 2015): when making interpretations, a person subjectively represents, in her/his mind, both personal preferences and what he/she considers to be socially acceptable and good. Thus, alongside the subjective individual context, experience is heavily affected by the consumer's social context that manifests in the opinions and experiences of other people.

Based on the above discussion, customer experience is here understood as, on one hand, an individual's internal and subjective perception and on the other a socially constructed and highly context-dependent entity that is susceptible to change and develop in terms of time. In relation to this, omni-channel banking focuses on the principles of consistency, optimization and seamlessness with the aim to make the customer experience as satisfactory as possible. With this theoretical understanding, we continue to explore customer experience empirically in the context of omnichannel banking services. In doing this, we let the data tell us how bank customers experience omnibanking services and what are the key factors related to their experiences. This helps us to create understanding of the present state of and future requirements of various different banking services and how they can be provided smoothly through different channels.

\section{METHODOLOGY}

The study was implemented as a qualitative field study that has characteristics of a phenomenological research strategy, in that the views and experiences of the users of banking services comprise the focus of interest rather than the actual level of service and its technical performance (Helkkula et al, 2012). We approach experience through a combination of two methods: Critical Incident Technique (CIT) and Event-Based Narrative Inquiry Technique (EBNIT). The former was developed by Flanagan (1954), and has been used e.g. in diverse service contexts to explore incidents that customers regard to be exceptionally positive or negative (Edvardsson and Roos, 2001). Critical incidents can 
be gathered in various ways, e.g. by personal or focus group interviews, or by direct or indirect observation, and typically respondents are asked to tell a story about an experience (Edvardsson, 1992). Even though a critical incident can also be a hypothetical one (Edvardsson and Roos, 2001) CIT has mainly been used to analyse lived experiences. Helkkula and Pihlström (2010) introduce EBNIT as a way to broaden the discussion about experiences to include both wider social and cultural aspects surrounding the storyteller (interviewee) and imaginary events that have not happened in real life, but which the storyteller can envision or fantasize on the basis of their lived experiences. Hence, EBNIT is a useful tool especially in creating new or revising old services. In addition to interviews, EBNIT has also been used in analyzing customer experiences through blog texts (Kelleher and Helkkula, 2010).

Consequently, this study examines consumers' experiences in using omni-channel banking services, with a focus on both actual and imagined experiences, by investigating the critical incidents that consumers identify either from their lived world, or through imagination. Empirical data, which is part of a wider service research initiative, was collected with 27 theme interviews and 14 diaries from users of omni-channel banking services. In interviews, the participants were encouraged to think about various different bank-related tasks they accomplish in their daily life and through different channels, such as ATMs, bank branches, online and mobile, and to tell about their behavior, thoughts and experiences related to them. After that, they were asked to describe more specifically in their own words "critical incidents", in this case positive and negative experiences in using omni-channel banking services. Furthermore, they imagined how such services could work in the future. In addition to interviews, a complementary set of data was collected through diaries. This way, consumers' daily operations can be taken into account as part of the service context and hence, relevant information can be obtained of their service experience as a whole (Heinonen et al, 2010), and of the critical lived or imagined incidents in particular (see also Kelleher and Helkkula, 2010). The participants were 
guided to write diaries on a daily basis during two weeks period, considering every occasion when they used any banking services. Their diary entries were based on free accounts of their experiences, thoughts, and events.

Participants, i.e. consumers who use different banking services regularly, were invited to participate in and sign up for the study on the researchers' Facebook pages. We encouraged all types of consumers to participate regardless of, for example, their level of banking service use experience, type/amount of bank services they use or social background, in order to assure as versatile and extensive data as possible. A total of 27 users signed up and all of them participated in the study. Participants were 20-70 years old, and both genders as well as various occupational groups were represented equally. All participants had used at least two different channels varying from bank desk, ATMs, online and mobile banking. Most common banking tasks among the participants were identified as checking balance, transferring money and paying bills. All participants were interviewed and asked for their interest to keep a diary. 14 participants agreed to keep a diary of their experiences for the period of two weeks. All interviews were conducted individually either face-to-face or by phone, and recorded and transcribed word for word. The transcribed interview data consists of a total of 305 pages. Diaries were delivered as word documents and the diary material included altogether 31 pages of text.

The data were analysed using theory-based content analysis method and both interviews and diaries were analysed in a similar way as text documents. The analysis was implemented first by reading through the text documents and focusing on the events and related experiences described by the participants. These were then categorized as positive critical experiences and negative critical experiences and further into actual and imaginary experiences involving the key aspects of omnichannel banking services. The analysis was based on our theoretical pre-understanding but also new 
themes were allowed to freely emerge from the data. NVivo software was used to facilitate the content analysis.

\section{FINDINGS}

Based on the data, critical incidents are categorized into actual and imaginary experiences and further divided into positive and negative. Next, the key factors related to each category are identified and illustrated with the aid of quotations from both the interviews and diaries.

Positive actual experiences

Four key factors were identified related to positive actual experiences: real-time operation, ease of use, the specific features and complementarity. First, real-time operation refers to availability of the services independent of time or location. This factor supports the theoretical assumption that customer experience is highly individual in nature and the customer wants to decide when and where s/he uses the service. This is illustrated in the following quotation:

"In my opinion, it is important that you're able to check your balance, you can pay bills, and you don't need to wait for the banker to wake up! For me, it's the best thing about it. [...] Exactly this that it is not time-specific. That they (banking services) are always available."(Man, 36 years).

Secondly, closely related to the real-time opearation is ease of use that refers to taking care of bankrelated tasks quickly and effortlessly. Third key factor creating positive experiences in customers are the specific features related to banking services, mostly in mobile bank. These included e.g. the follow-up of the consumption and visual image of the service. 
"A very positive surprise was the feature that shows you what you spend your money on, it shows the categories of your consumption. I think it has been carried out well. It shows it nicely, with circles of corresponding size, the categories, how much money you have spent on different types of things. I think it's great." (Man, 39 years, excerpt from a diary).

Fourthly, the importance of complementarity between different banking services also became clear as respondents use different channels to accomplish different bank-related tasks. However, the importance of mobile is clearly growing compared to other services, as the following quotation reveals:

"Mobile has changed it, made it much easier. Before, in the days of computers and modems, when you got your first internet bank access, oh boy it was so difficult. But nowadays it's so quick and easy, painless." (Man, 29 years).

Negative actual experiences

Altogether five key factors related to negative actual experiences were identified in the data analysis. First, dysfunctionalities of the service are one major cause of negative experiences for omni-channel bank service users. If there are any uncertainty in using the service it causes a lot of confusion for the users as the following quotation illustrates:

"When the service isn't working well, when it's e.g. buffering. Or, when a payment transaction has failed for some reason, it causes irritation and insecurity [...] In my own bank, there has been this thing two times a row that my payment transaction was unfinished even though it has showed me that 
the transaction was successful. And then later on, I've found out on my internet bank that the payments haven't been finalised, so that has caused a lot of annoyance." (Woman, 20 years).

Secondly, technical defects are another feature that irritates the customers. If there are continuous problems, it may decrease or even inhibit the use of the specific bank service:

"Of course, if it's poorly coded, if it has a lot of all kinds of bugs, errors, so then it's sort of natural that I don't want to use it. [...] And then the situations where an app froze your phone so that you had to take the battery out to get the phone working. That made me mad." (Man, 28).

Thirdly, incoherence of the service was seen as one big negative factor as the next quotation exposes:

"If the logic (of a mobile bank app) doesn't make any sense, that you don't immediately get it how to use it, to find what you're looking for, if you need to search for it. That is annoying. " (Woman, 33).

Fourth, delays in service was identified as a factor that angers many users. Nowadays customers are inpatient and expect real-time operation from their banking services. Finally, the incompatibility between banks is closely related to the delays in service as it often results in delayed money transfers:

"There has been this situation that my spouse, who has her account in a different bank than I do, has asked me to transfer money to her, and then I've done it. And then a moment later she's at a cashier: no money. And she checks her balance and oh, the money hasn't arrived yet. I mean really, does it still need to be so difficult, to get money transferred between banks quickly?" (Man, 29).

Positive imaginary experiences 
In case of imaginary experiences, i.e. what the users of omni-channel banking services expect and envision the future banking services could be at best, the customers often use their previous experiences as a basis on which they build imaginary experiences on. Firstly, in our data social aspects were emphasized, e.g. being a kind of pioneer in using new services, and getting recommendations from other users as demonstrated in the following quotation:

"I started to think how to utilize the social aspect, sort of, if they would give examples of the app, someone's personal, like "I use it like this and oh what wonderful things I learnt from it!' [laughs] 'I used this app and saved 100 euros per month!' These types of things would be really good! I could learn how to make best out of it." (Man, 39 years).

Secondly, context-awareness was seen as a highly important feature in the future banking services, for example:

"I think that it's more and more coming, the place sensitivity and context-awareness in general. That the apps somehow know when to wake up just when you need them, or they interpret your speech or whatever is going on in that situation." (Man, 39 years).

Thirdly, different technical characteristics were suggested that would make the use of banking services even more automatic and easy. There were quite innovative features suggested, e.g.:

"In the future, you could have this kind of a biometric identification, basing on your iris or your fingerprints" (Man, 28 years). 
Fourthly, proactivity of the service became evident from the data as the users expected future banking services to be able to predict their behavior and to adjust accordingly.

"Like it could, somehow, in the future, collect data from the user. For example that I pay most of the bills on payday and all the invoices would be processed as direct payments and I could trust that everything is paid on payday." (Man, 29 years).

Also virtual aspects were seen as an important in the future, which is closely related to real-time operation and context-awareness:

"Video conferences or controlling a camera or whatever with your eyes or something. For me they're interesting scenarios that you have this virtual world through which all stuff happens." (Man, 36 years).

Usability was identified as one of the key factors of positive imaginary experience, specifically in the case of older people. Many respondents saw usability and ease of use as necessary so that the services will be used by everybody:

"My mum for example, she doesn't have a smartphone, but just the internet bank, and for her it's incredibly difficult to use. So, it needs to be easier to use." (Man, 29 years).

Tailoring of the service so that the banking services could offer e.g. special discounts or targeted information for the user based on his/her profile was also found important among respondents. Finally, complementarity of different banking services were discussed in the imaginary experiences 
as the respondents saw that the traditional way of taking care of banking with bank branches, ATMs, computers etc. will be mostly replaced by mobile in the future.

"In the future, I shouldn't need to visit the office. If I take a mortgage, for example, all the paperwork could be somehow taken care of with your phone." (Woman, 33 years)

Negative imaginary experiences

In negative imaginary experiences, the respondents expressed negative scenarios or fears concerning future banking services. Related to this, four key factors were be identified from the data. Firstly, security issues were seen as a highly critical issue. Fear of security breaches, somebody stealing money from your account or misuse of mobile banking app were often pointed out, among other security issues:

"About the security stuff, I know that they've used a scanner to get money out of your phone [mobile payment app] in a bus, so that makes you think would it be a genuine threat, that there will be these scanners with which you can steal money from the phone." (Man 36 years).

Secondly, complexity of the service was one key factor in negative future scenarios as illustrated in the following quotations:

"If it's like a really complicated service, and when you use it for the first time you would feel like it's not going to work, then maybe you try it once, but if it wouldn't work, then I wouldn't try to use it again." (Woman, 36 years) 
"Everything extra that there might be, it makes it more confusing, like if you think about elderly users. It should be as simple as possible, nothing extra, nothing commercial, no animations, videos, ads or anything like that." (Woman, 37 years, excerpt from the diary).

Thirdly, social aspects were pointed out as the respondents felt that their circle of acquaintances could strongly influence their use of future banking services.

"It does have an effect, I mean if 90\% of your friends would bash an app, say that it's bad, complete waste of time and don't even bother, so I'm quite sure I wouldn't use it then. So there is a social pressure." (Man, 29).

Lastly, uncertainty was identified as the key factor referring to a fear of what future technologies may enable people to do, for example:

"You sort of think about identity theft. That it's related to this feeling of something unknown, bad, doubt. Because overall I'm a skeptical person." (Woman, 37).

Overall, the features identified above are closely related to each other and even partly overlapping. However, they reveal the present state of consumers' experiences (both actual and imagined) in the context of omni-channel banking services. The main findings are summarized and illustrated in Figure 1 and they will be next discussed in more detail.

Insert here Figure 1. Customer experience in omni-channel banking services.

\section{DISCUSSION}


Based on our data, four main categories can be identified among omni-banking service customers as actual positive and negative experiences and imagined positive and negative experiences that are influenced by past, present and future dimensions (see Figure 1). This implies that focusing only on the present experiences is not enough but it is important to pay attention to also past and imagined future experiences as well.

Firstly, in the case of actual experiences, the dominating key factors relate to ease vs. difficulty of using the omni-banking services. If the services seem too complicated, are not working properly and do not complement each other in a smooth and comprehensive way, the customers easily reject them and choose another, more easy-to-use service. In case of omni-channel banking services, this could mean that if the past experiences have been negative, i.e. for example the mobile banking service has been difficult to use and included technical defects, it may also influence the present experience and future expectations. Then, instead of starting actively use mobile banking along with other services, the customer may return to using only online or even personal banking services.

On the other hand, concerning imaginary experiences, positive aspects relate to customers being pioneers, trailblazers, which appreciate the idea of being among the first ones using new services and having an image and the mental picture of a modern customer. This is closely related to social aspects, i.e. showing others (e.g. friends, family members, colleagues) that they are ahead of others in adopting future services. The social aspect is important and may have a strong impact on service use; even if the service does not function perfectly, this aspect may even compensate it. This can be utilized by banking service providers, as they might find it reasonable to launch new services as fast as possible to attract "trailblazers" and then develop them further based on users' experiences and other market information. Negative imaginary experiences relate mostly to different risks of using future services, 
for example in terms of security and confidentiality issues, as the service is closely related to the customers' money and privacy.

Interestingly, according to our findings, the key features or principles of omni-channel did not come up in the consumers' interviews or diary data. Even though participants were encouraged freely to tell about their experiences with diverse set of banking services, seamlessness, optimization or consistency were not brought out neither in positive or negative, actual or imagined experiences. One reason for this can be that the in the eyes of the bank customers, banking services in different channels are still seen and used as separate services. This is in line with the study of McKinney (2014) suggesting that most bank customers prefer to perform their transactions through one single channel and go to another channel only when the preferred one fails. It creates a challenge for banks in their attempts to develop services that create a seamless, optimized and consistent customer experiences and this way improve the customer perceived value and loyalty towards the bank, especially when customers are not yet consciously willing to utilize the possibilities of omni-banking services.

\section{CONCLUSIONS}

The objective of this study was to create in-depth understanding of how do customers experience omni-banking services and what are the key factors related to their experiences. Thus, it contributes to the existing bank marketing research by exploring customer experiences in a highly topical omnibanking context. As suggested by Hoele et al. (2012), previous studies in banking context have mostly researched banking channels separately. For example, Klaus and Nguyen (2013) explored the role of customer experience in online retail banking services and many studies have focused on different aspects of mobile banking (see e.g. Laukkanen and Lauronen, 2005; Thakur, 2014; Sahoo and Pillai, 
2017). Hence, this paper extends these studies by adopting a more extensive, omni-channel perspective on bank services.

As a result of our empirical study among multiple banking service customers, this study identifies both actual critical events and imaginings, positive and negative, that are related to the forming of customer experiences and suggests that these are highly important in understanding customers in a digitalizing financial services world. By studying customer experiences in a specific context, this study contributes also to current service experience discussion. As noted by Jaakkola et al, (2015), there has been a lack of empirical investigations regarding customer experience within different types of industries, and this study is one of the attempts to gain more in-depth understanding of the topic. In addition, this study investigates customer experience as a broader concept, including both actual and imaginary perceptions of an individual. In line with Helkkula et al, (2012), the findings of this study indicate that customers' experience is not formed only through present experiences, but is also influenced by their past experiences as well as future expectations.

In relation to omni-channel approach, academic literature of this emerging phenomenon in different contexts (except for studies in retailing industry) has still been scarce (Rosman, 2015; Saghiri et al., 2017). However, it has recently been suggested that the omni-channel approach is ideal specifically for the banking industry, based on the assumption that consumers conduct the same banking tasks on many devices and switch between them while doing so (see Rosman, 2015). According to our empirical findings, this is not necessarily the case, at least not yet. On the contrary, our research results are in line with the study of Rosman (2015) suggesting that customers typically use one channel when conducting their everyday banking tasks and they do not consider seamlessness, optimization or consistency (as key principles of omni-channel) as important while using banking services. Our findings suggest that in practice, customers still think about different channels as separate and use the one they find most suitable in each situation. Thus, in banking service context 
multi-channel view seems to be more close to the consumers' reality than omni-channel, which means that banks still have a lot of work to do in developing value creating customer experience across various different channels.

Based on the above discussion, this study provides several implications for banks and other financial service providers in developing their omni-channel design. Firstly, it is important to notice that customer experience is extensive and multi-dimensional phenomenon including past, present and future dimensions as well as actual and imaginary aspects. Many banks are already using short surveys after each customer encounter to find out whether it was a good or poor experience and some are using focus groups and other customer-involved methods to learn how to create ideal customer experience and optimal value. In these situations it is important to focus not only on present actual experience of the customer but to try reveal also imaginary experiences (possibly influenced by other people and future expectations) to get a more holistic view.

Secondly, the findings indicate that customers seem to favor mobile banking services more and more. The key seems to be that the service is easily accessed, easy to use and functions flawlessly regardless of time and location. In addition, customers expect banks to increasingly utilize the possibilities of digitalization, as things such as proactivity, anticipating customer needs, as well as tailoring and customization of services were regarded important. In other words, in order for customers' to gain value from the services, they have to meet their specific, yet rapidly changing needs and banks need to be constantly aware of these.

Thirdly, the social aspect is highly important, as other customers' experiences, recommendations and comments play a big role in how customers perceive the services. Hence, banks should consider the ways in which they can encourage their customers to tell about their positive experiences to others. 
Building a social dimension into the service could be one viable solution, i.e. make it visible to others that "this person is using our new and progressive banking service".

Fourth, our findings support the findings of the study of omni-channel banking in Sweden suggesting that an omni-channel approach still seems to lack relevance for the simple everyday banking tasks (see Rosman, 2015) that were the most commonly discussed banking tasks among the consumers also in this study. Bank customers did not show a need to switch between channels, which implies that the banks should focus on utilizing and enhancing the strengths of each channel instead concentrating purely on omni-channel principles. In addition, when considering omni-channel, banking tasks requiring more time, information and motivation could be the ones banks should think about first when they are developing their services towards omni-channel design.

Finally, when discussing superior customer value and underlying experiences, it is of significance to emphasize that banks need to better understand their customers, their everyday lives and bank services' role in them. Hence, banks need to integrate their services to customers' value creation processes; so that customers can gain optimal value from the services in different situations that they face in their everyday lives. This is anything but easy, but as our findings indicate, customers' positive experiences seem to stem from situations where the service is seamlessly integrated to their lives. In addition, anticipating how customers' everyday life will change in the future, and how the service should change accordingly, is important.

As any qualitative study conducted in the specific context, this study is not without limitations. The study explored customer experiences in omni-channel banking services, i.e. in the context of different banking services delivered through various channels, and it focused on experiences of critical incidents described by the participants, not on key principles of the omni-channel approach 
(seamlessness, optimization and consistency). Thus, the findings highlight the views of bank customers and cannot be generalized to other services in other contexts. However, the participants represent a heterogeneous group of people with many different kinds of experiences of omni-channel banking services, which ensures an extensive and versatile data with plausible outcomes related to the studied phenomenon. In addition, although different contextual factors such as customer demographics, social and financial situation and cultural and psychological features have been identified as important influencers of customer experience in the previous research, they did not appear explicitly in the analysis of the empirical data in this research. However, these factors most like affect the behavior and experiences beneath the surface. Therefore, in the future, a more detailed study focusing specifically on these aspects would reveal their influence more clearly. Furthermore, this study provides a fruitful starting point for future quantitative studies in the field of omni-channel by pointing out some key factors that still need further investigation. For example, quantitative methods could be used to verify the usage patterns of consumers in different banking services. Finally, studying omni-channel approach in different context and with different types of services is needed to create more profound understanding of the phenomenon.

\section{REFERENCES}

Carroll, D. and Guzman, I. (2015) The new omni-channel approach to serving customers: Strategy implications for communications service providers. https://www.accenture.com/been/ /media/Accenture/Conversion-Assets/DotCom/Documents/Global/PDF/Industries_2/accenture$\underline{\text { new-omni-channel-approach-serving-customers.pdf [Accessed 10.9.2018] }}$

Constantinides, E. (2004) Influencing the online consumer's behavior: The web experience. Internet Research, 14(2): 111-126. 
Dube, A. and Helkkula, A. (2015) Service experiences beyond the direct use: Indirect customer use experiences of smartphone apps. Journal of Service Management 26(2): 224-248.

Edvardsson, B. (1992) Service breakdowns: a study of critical incidents in an airline. International Journal of Service Industry Management 3(4): 17-29.

Edvardsson, B., and Roos, I. (2001) Critical incident techniques: Towards a framework for analysing the criticality of critical incidents. International Journal of Service Industry Management 12(3): 251268.

Flanagan, J. C. (1954) The critical incident technique. Psychological bulletin 51(4).

Frow, P. and Payne, A. (2007) Towards the 'perfect' customer experience. Journal of Brand Management, 15(2): 89-101.

Gentile, C., Spiller, N. and Giuliano, N. (2007) How to sustain the customer experience components to co-create value with the customer. European Management Journal 25(5): 395-410.

Heinonen, K., Strandvik, T., Mickelsson, K.-J., Edvardsson, B., Sundström, E. and Andersson, P. (2010) A customer-dominant logic of service. Journal of Service Management 21(4): 531-548.

Heinonen, K., Strandvik, T., and Voima, P. (2013) Customer dominant value formation in service. European Business Review 25(2): 104-123.

Helkkula, A. and Kelleher, C. (2010) Circularity of customer service experience and customer perceived value. Journal of Customer Behavior 9(1): 37-53.

Helkkula, A., Kelleher, C. and Pihlström, M. (2012) Practices and experiences: challenges and opportunities for value research. Journal of Service Management 23(4): 554-570.

Helkkula, A. and Pihlström, M. (2010) Narratives and metaphors in service development. Qualitative Market Research: An International Journal 13(4): 354-371.

Hoehle, H., Scornavacca, E. and Huff, S. (2012) Three decades of research on consumer adoption and utilization of electronic banking channels: A literature analysis. Elsevier 54(1): 122-132. 
Holbrook, MB. and Hirschman, EC. (1982) Hedonic consumption: emerging concepts, methods and propositions. Journal of Marketing 46 (3): 92-101.

Jaakkola, E., Helkkula, A. and Aarikka-Stenroos, L. (2015) Service experience co-creation: conceptualization, implications, and future research directions. Journal of Service Management 26 (2): 182-205.

Kelleher, C. and Helkkula, A. (2010) Virtually speaking-customer to customer communication in blogs. Journal of Applied Management and Entrepreneurship 15(3).

Klaus, P. and Nguyen, B. (2013) Exploring the role of the online customer experience in firms' multichannel strategy: An empirical analysis of the retail banking services sector. Journal of Strategic Marketing, 21(5): 429-442.

Komulainen, H., Saraniemi, S., Ulkuniemi, P. Marianne Ylilehto, (2018) End-customer value restructuring the financial service supply chain. Marketing Intelligence \& Planning, 36(6): 709-720 Laukkanen, T. and Lauronen, J. (2005) Consumer value creation in mobile banking services. International Journal of Mobile Communications 3(4): 325-338.

Lemke, F., Clark, M. and Wilson, H. (2011) Customer experience quality: an exploration in business and consumer contexts using repertory grid technique. Journal of the Academy of Marketing Science, 39(6): 846-869.

Light, J., McFarlane, A., Barry, K. and Ruotsila, I. (2016) Seizing the opportunities unlocked by the EU's revised payment services directive. https://www.accenture.com/t20160505T180127_w_/ca$\underline{\text { fr/_acnmedia/PDF-15/PSD2-Seizing-Opportunities-EU-Payment-Services }}$

Directive\%20(1)\%20(1).pdf, [Accessed 10.12.2017].

Lähteenmäki, I. and Nätti, S. (2013) Obstacles to upgrading customer value-in-use in retail banking. International Journal of Bank Marketing 31(5): 334 - 347.

McColl-Kennedy, J. R., Cheung, L. and Ferrier, E. (2015) Co-creating service experience practices. Journal of Service Management 26(2): 249-275. 
McKinney, T. (2014). Omni-channel banking customer experience: Forget what you thought you knew about channels.

Marketing Science Institute (2016), "Research priorities 2016-2018”, available at: www.msi.org [Accessed November 10, 2017].

Rosman, T. (2015). Investigating omni-channel banking opportunities in Sweden: From a user perspective. KHT Royal Institute of Technology, School of Computer Science and Communication. Saghiri, S., Wilding, R., Mena, C., \& Bourlakis, M. (2017). Toward a three-dimensional framework for omni-channel. Journal of Business Research, 77: 53-67.

Sahoo, D. and Pillai, S. (2017) Role of mobile banking servicescape on customer attitude and engagement: An empirical investigation in India. International Journal of Bank Marketing, 35(7): $1115-1132$.

Shaikh, A. A., and Karjaluoto, H. (2015) Mobile banking adoption: A literature review. Telematics and Informatics 32(1): 129-142.

Skan, J., Dickerson, J. and Masood, S. (2015) The future of fintech and banking: Digitally disrupted or reimagined? www.accenture.com, [Accessed 15.11.2017].

Tam, C. and Oliveira, T. (2017) Literature review of mobile banking and individual performance. International Journal of Bank Marketing 35(7): 1044-1067.

Thakur, R. (2014) What keeps mobile banking customers loyal? International Journal of Bank Marketing, 32(7): 628-646.

Tynan, C. and McKechnie, S. (2009) Experience marketing: A review and reassessment. Journal of Marketing Management 25: 501-517.

Van Dijk, G., Minocha, S. and Lang, A. (2006). Multi-channel consumer behavior: Online and offline travel preparations. CHI 2006, 1457-1462. 
